\title{
Incommensurate vibro-acoustic performance due to in-process blank holder force variation during deep drawing process
}

\author{
Vamsi Krishna Balla ${ }^{\mathrm{a}, *}$, Elke Deckers ${ }^{\mathrm{b}, \mathrm{c}}$, Stijn Jonckheere ${ }^{\mathrm{a}, \mathrm{c}}$, Bert Pluymers ${ }^{\mathrm{a}, \mathrm{c}}$, \\ Wim Desmet ${ }^{\mathrm{a}, \mathrm{c}}$ \\ ${ }^{a}$ Department of Mechanical Engineering, KU Leuven, Celestijnenlaan 300-box 2420, \\ 3001 Leuven, Belgium \\ ${ }^{b}$ Department of Mechanical Engineering, KU Leuven, Campus Diepenbeek \\ Wetenschapspark 27, 3590 Diepenbeek, Belgium \\ ${ }^{c}$ DMMS Lab, Flanders Make
}

\begin{abstract}
Single-stage forming is widely used in automobile industry due to less cycle times, cost-effectiveness and ease of implementation. The continuously adaptable blank holder force (BHF) systems help produce defect-free components during the deep drawing process. However, this manufacturing process induces a significant amount of variability both at geometry and functional performance of the component. A systematic investigation of the effect of small geometrical changes on the vibro-acoustic properties is carried out using a combination of simulations and experiments. The influence of BHF and friction coefficient on vibro-acoustic properties is investigated through forming simulations. The forming analysis results - geometry profile and thinning - are used as an input to predict the vibro-acoustic behaviour of the formed component. The small geometric profile and thickness variations are significant and affect radiated noise-directivity pattern and sound power levels by $1.4 \mathrm{~dB}$. Two physical components are manufactured using a single-stage deep drawing process. The natural frequencies and mode shapes obtained in free-free boundary conditions vary between the two components up to $20 \%$ for the first six flexible modes. The sound power levels between the actual parts varied by $2 \mathrm{~dB}(\mathrm{~A})$. Finally,
\end{abstract}

*Corresponding author : vamsikrishna.balla@kuleuven.be

Preprint submitted to Elsevier

July 21, 2020 
it is shown that the vibro-acoustic variability is more pronounced at higher frequencies.

Keywords: Deep drawing, process parameters, geometric variations, natural frequency, sound power

\section{Deep drawing process \& Sources of variability}

Deep drawing [1] is one of the most commonly used manufacturing processes in various industries like automobile, medical and food processing, etc. Deep drawing is a sheet metal forming process in which a blank is drawn into a

5 die cavity using a punch. This process involves significant transformations to achieve the desired shape. Deep drawing is carried out either in a single stage or in multiple stages depending on the depth of the component. The component is manufactured in multiple stages when the relative depth of the component is too high, and the deformations would exceed the formability of materials in a singlestage forming. Single-stage deep drawing is widely employed, as it involves a lower cost of manufacturing although variability due to the manufacturing process is high. The technical report [2] showed that the total stamping process variation is the sum of part-to-part variation and begin-to-end variations. A study of 36 body panels ( 6 per die set $\times 6$ die sets $=36$ total panels) from seven different automobile manufacturers (GM, Toyota, Chrysler, Nissan, Ford, Opel \& Renault) were analysed and found that process variation index $C_{p k}$ target value 1.33 was not achieved. Hancock et al. [3] showed that part-topart variation contributed to $21 \%$ of the total variation. The variability of the batch produced components is attributed to process parameter variations of the manufacturing process.

\subsection{BHF \& friction coefficient}

Siekirk [4] established that five sheet metal forming process variables - blank size, blank location, binder force, material thickness and lubrication - determine sheet metal quality. Yossifon [5] studied the strain variations of a cylindrical 
cup that is manufactured using two constant BHF $(6.8 \mathrm{kN}$ and $12.4 \mathrm{kN})$ values. The defect-free components are manufactured using an acceptable BHF-stroke zone located between two critical curves (wrinkling locus and rupture locus). Siegert [6] showed that using a closed-loop control with friction force as a control parameter and $\mathrm{BHF}$ as a feedback parameter, it is possible to manufacture so components that are free of tears and wrinkles. The close loop control automatically adjusted the BHF values to achieve the desired friction force. Thomas [7] showed that the blank holder force variation that occurs during the mass production could be caused by wear in the die or press, misalignment of the tooling and changes in the material thickness. Karima et al. [8] showed that the blank holder force increased by $15 \%$ when the blank base thickness changed by 0.004 inch. Voss [9] studied the effect of galling wear on the punch force variation due to friction changes. Koh et al. [10] showed that the stamping force varied due to the change in the cushion pressure. It is evident from the work of the above researchers that $\mathrm{BHF}$ values adjust (in a specific acceptable range) due to the changes in the process parameters, to produce right quality products.

\subsection{Springback}

Achieving the desired dimensional accuracy is a challenge considering the complexity associated with the springback phenomenon. Springback occurs mainly due to the recovery of elastic deformation of the sheet metal after plastic forming. To predict springback values accurately, Prior [11] carried out a combination of explicit and implicit finite element method simulations. Lee [12] studied the effect of element size and the number of corner elements on springback simulation. Tang [13] reviewed the state-of-art of sheet metal simulations and suggested new methods that are possible due to significant progress of hardware and software systems. Echempati et al. [14] studied the springback of three different aluminium alloys. They carried out numerical studies using LS Dyna and Optris and validated simulation results with experimental results. Their research showed that the springback is dependent on the punch velocity, binder pressure and the friction coefficient. Hence, the aforementioned phenom- 
ena beget dimensional variability that is most often a concern for the process engineers. However, the effect of these changes on various functional performance metrics (durability, crash, and vibro-acoustics) of the manufactured part is seldom investigated.

\subsection{Vibro-acoustic variability}

The control of vibro-acoustic variability is of great significance in achieving a robust design. Hence, various researchers attempted quantification of variability both at vehicle level and individual component levels. Kompella et al. [15] measured structure-borne and air-borne transfer functions of 99 nominally identical passenger cars and 57 nominally identical pick-up trucks and showed up to $10 \mathrm{~dB}$ variation occurred among the vehicles. Hills et al. [16] investigated on a rather large sample size of cars (1130) to understand the sound pressure level (SPL) variations. Their study showed air-borne cabin noise, and road-noise among the vehicles varied up to $5 \mathrm{~dB}$ and $15 \mathrm{~dB}$ respectively. Dev et al. [17] carried out a modal analysis of an oil pan using the geometry obtained from forming simulation results. Balla et al. [18] showed that significant changes in the geometry profile and thickness distribution occurred in the single-stage deep-drawn components. They demonstrated that the mode shapes of the physical parts are significantly altered when compared to the base CAD finite element model results. Balla et al. [19] demonstrated that the actual part's vibro-acoustic behaviour is very different when compared to the simulation results obtained using a nominal CAD model.

\subsection{Motivation}

The weight of sheet metal is approximately $23 \%$ and $65 \%$ weight of the vehicle and BIW weights, respectively [20]. Hence, reduction of variability is so achieved by controlling the variations of the associated manufacturing. It is evident from the work of the above researchers that the variation in the stamping process is quite significant due to in-process parameter changes. The variation occurs because of usage of a closed-loop manufacturing process that adjusts the 
BHF values due to the changes of blank thickness variation, wear in the die or press misalignment. The process parameters affect geometric profile and thickness distribution variations that in turn can have an impact on the vibro-acoustic properties of the manufactured components. However, a limited amount of research has explored the influence of deep drawing process parameters on the vibro-acoustic performance. Hence, in this work, an attempt is made - after validating geometry profile and thickness variations results of the present study with the literature - to relate the process parameter changes to vibro-acoustic behaviour.

\subsection{Outline}

The outline of the paper is as follows; The theory of deep drawing analysis is briefly presented in Section 2. The forming simulation results of a reference geometry (cylindrical cup) and also of an oil pan look-alike component using implicit finite element formulation are discussed. The vibro-acoustic performance behaviour of the formed oil pan components and their sensitivity to process parameters is studied in Section 3. The manufacturing process and dimensional measurements of the oil pan component, to assess the accuracy of the actual manufactured part, are explained in Section 4. In Section 5, vibro-acoustic results obtained through measurements of the actual oil pan component using an impact hammer and a modal shaker are described. In the last section, the conclusions of the present study and the scope of future research work are mentioned.

\section{Simulation of the deep drawing process}

Section 2.1 presents the theory of deep drawing simulation briefly. In Section 2.2, the deep drawing results of the reference cylindrical cup geometry are discussed. The correlation of the plastic stain distribution, eigenfrequencies and FRFs with the numerical and experimental is presented. Section 2.3 describes the oil pan simulation results with two different process parameters. The com- 
parison of geometry and thickness variations between the two simulation cases is presented.

\subsection{Theoretical formulation}

In this section, the theory of deep drawing simulation is briefly presented. The reader is referred to COMSOL Multiphysics theory manual [21] for more detailed information. As the deep drawing process involves a large amount of deformation, large plastic strains are considered. In the present work, the deep drawing process is assumed as a quasi-stationary process, and hence inertial effects are neglected. The yield criterion is chosen to be Von-Mises stress and is given by the following equation

$$
Q=\sigma_{\text {mises }}-\sigma_{y s},
$$

115

where $\sigma_{y s}$ is the stress at each time step.

To carry out deep drawing simulations, a total Lagrangian formulation is used. Hence, the computed stresses and deformation are expressed as a function of material configuration instead of using the current position in space. The material properties are referred to a coordinate system based on the material frame. The spatial coordinate $\mathbf{x}$ can be expressed in terms of initial material coordinate $(\mathbf{X})$ as

$$
\mathbf{x}=\mathbf{x}(\mathbf{X}, t) .
$$

The deformed position is expressed in the same coordinate system. Hence, it can be written as

$$
\mathbf{x}=\mathbf{X}+\mathbf{u}(\mathbf{X}, t)
$$

The displacement( $\mathbf{u})$ is considered as a function of the material coordinates $(\mathbf{X}, \mathbf{Y}, \mathbf{Z})$. The deformation gradient tensor $F$ can be expressed in terms of displacement gradient as

$$
F=\frac{\partial \mathbf{x}}{\partial \mathbf{X}}=\nabla \mathbf{u}+I,
$$


In geometrically nonlinear analyses such as deep drawing simulation, the stress is interpreted as second Piola-Kirchhoff stress (S) where both force and area are represented in the material configuration. A stationary analysis is carried out to simulate the deep drawing process as given by the following equation

$$
\nabla \cdot F S+F_{V}=0
$$

120

\subsection{Cylindrical cup results}

The deep drawing analysis of a cylindrical cup is performed to the simulation methodology. Table 1 shows the geometrical dimensions, material properties, process parameters, and these are based on [22]. Hence, a direct comparison of the cylindrical cup is shown in Figure 1, and only one-quarter of the model is analyzed to take advantage of symmetry. The blank is made of DP600 steel.

\begin{tabular}{lr|lr}
\hline Parameter & Value & Parameter & Value \\
\hline Blank radius $(B R)$ & $50 \mathrm{~mm}$ & Young's modulus $(E)$ & $200 \mathrm{e} 9 \mathrm{~N} / \mathrm{m}^{2}$ \\
Punch radius $(P R)$ & $25 \mathrm{~mm}$ & Initial Yield stress $\left(\sigma_{y s 0}\right)$ & $416 \mathrm{MPa}$ \\
Die radius $(D R)$ & $26.44 \mathrm{~mm}$ & Tangent modulus $\left(E_{T i s o}\right)$ & $0.5 \mathrm{e} 9 \mathrm{~N} / \mathrm{m}^{2}$ \\
Blank thickness $(t)$ & $0.97 \mathrm{~mm}$ & Blank Holder Force $(B H F)$ & $45 \mathrm{kN}$ \\
Punch nose radius $\left(r_{p}\right)$ & $6 \mathrm{~mm}$ & Density $(\rho)$ & $7800 \mathrm{~kg} / \mathrm{m}^{3}$ \\
Die shoulder radius $\left(r_{d}\right)$ & $3 \mathrm{~mm}$ & Friction coefficient $(\mu)$ & 0.12 \\
Cup height $(h)$ & $24 \mathrm{~mm}$ & Poisson's ratio $(\nu)$ & 0.3 \\
Working clearance $(w)$ & $1.44 \mathrm{~mm}$ & & \\
\hline
\end{tabular}

Table 1: Geometry and process parameters used in deep drawing simulation of cylindrical cup [22].

The punch, die, and blank holder are considered to be rigid, and hence plasticity effects are included only for the blank material. The blank sheet is supported by a blank holder that exerts the required force to enable the deep drawing process. In this analysis, three contact pairs are defined: i) punch and blank ii) die and blank iii) blank holder and blank. The punch, die and blank 


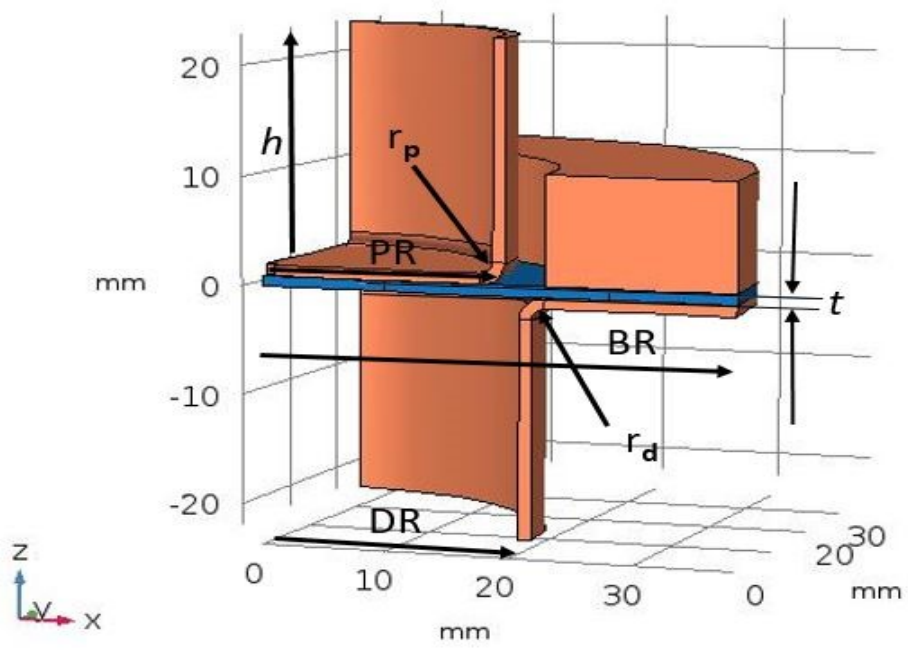

Figure 1: The geometry set-up of a cylindrical cup deep drawing simulation.

holder are identified as sources and the blank as a destination in their corresponding contact pairs. The destination mesh, i.e. blank mesh, is much fine (by about four times in comparison to the source mesh) to eliminate non-physical oscillations of the contact pressure. The blank is meshed using hexahedral (brick) quadratic elements with $0.1 \mathrm{~mm}$ element size. The thickness of the blank is modelled using four layers to capture the strain accurately. The punch, the blank holder and the die are meshed with tetrahedral elements. The punch nose radii and die shoulder radii are modelled with finer mesh, to avoid stress concentration that would lead to convergence issues. The penalty approach [23] is used to compute the contact pressure. The contact pressure penalty factor $\left(\boldsymbol{p}_{n}\right)$ defined in the simulation needs to balance convergence issues and minimal penetration and is defined as follows:

$$
\boldsymbol{p}_{n}=\frac{E_{\text {char }}}{h_{\text {min }}} * \text { Elem }_{\text {size }}
$$

where $E_{\text {char }}$ is characteristic stiffness and $h_{\min }$ is the smallest element size in a given time-step. A direct, fully coupled solver based on the automatic Newton method is used as it can determine the damping factor in each iteration. 
The deep drawing simulation time is 2 seconds. The computational time on a WINDOWS 64 bit machine with 8 GB RAM is approximately 11 hours.

Figure 2a shows the displacement results of the deep drawing analysis. The deep drawing analysis is complete, and the intended design depth of the cup is realized. Figure $2 \mathrm{~b}$ shows the effective plastic strain distribution within the component. The highest plastic strain (0.53) induced during the deep drawing process matches closely to that of the reference value of 0.52 . The effective plastic strain distribution pattern along the component is also comparable to the experimental results of the reference [22].
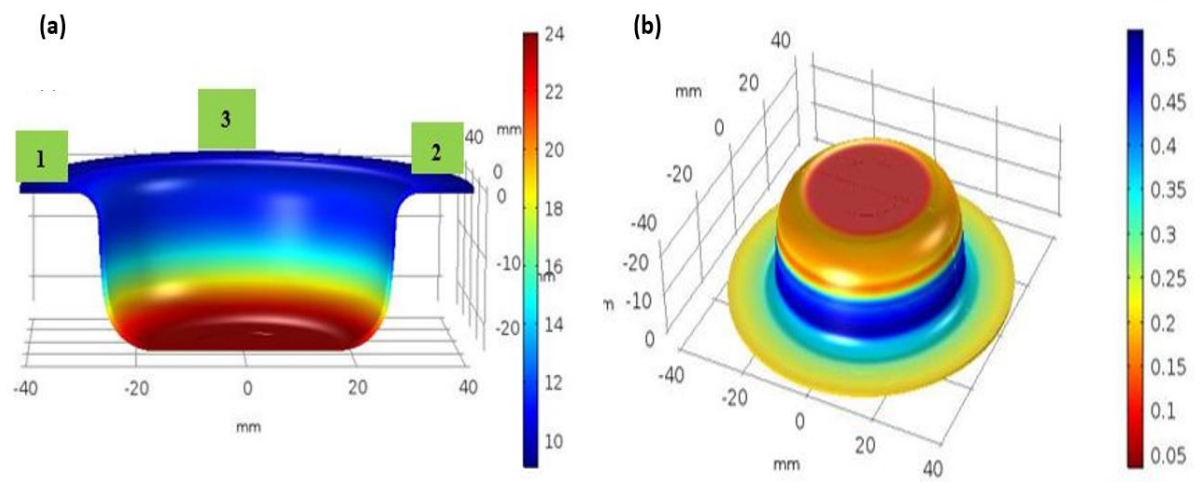

Figure 2: Deep drawing analysis results of a cylindrical cup a) displacement b) effective plastic stain.

The resultant FE model of deep drawing simulations considers both geometric and thickness variations that occur during the actual manufacturing process. To assess the validity of the current FE results, a comparison of the natural frequencies with the experimental results mentioned in [22] is carried out, and results are shown in Table 2 . The match between the experimental and current FE results is good since the highest percentage of deviation between the results is about $4 \%$. To further validate the current simulation methodology, a FRF comparison between the FE model and the experimental measurement is carried out. As described in [22], the experimental set-up consists of a physical prototype of a deep-drawn cylindrical cup that is suspended using a set of soft springs 


\begin{tabular}{cccc}
\hline Sl.No. & Experiment $[22]$ & Present study & \% difference \\
\hline 1 & 3913 & 3990 & -2.0 \\
2 & 4024 & 4034 & -0.2 \\
3 & 4113 & 4181 & -1.7 \\
4 & 4130 & 4227 & -2.3 \\
5 & 4262 & 4357 & -2.2 \\
6 & 4914 & 5038 & -2.5 \\
7 & 4925 & 5091 & -3.4 \\
8 & 5022 & 5129 & -2.1 \\
\hline
\end{tabular}

Table 2: Comparison of natural frequencies $(\mathrm{Hz})$ between current $\mathrm{FE}$ and experimental results.

to represent free-free boundary conditions. The cup is excited at one point using an impact hammer and responses are measured at two other points using a laser vibrometer. These excitation and response points are shown in Figure 2a.

Figure 3 shows the FRF comparison between measurement and present study results at point- 2 and their amplitude levels correlate within $\pm 5 \%$. Hence, it can be stated that the the simulation model well represents the global behaviour of the cylindrical cup.

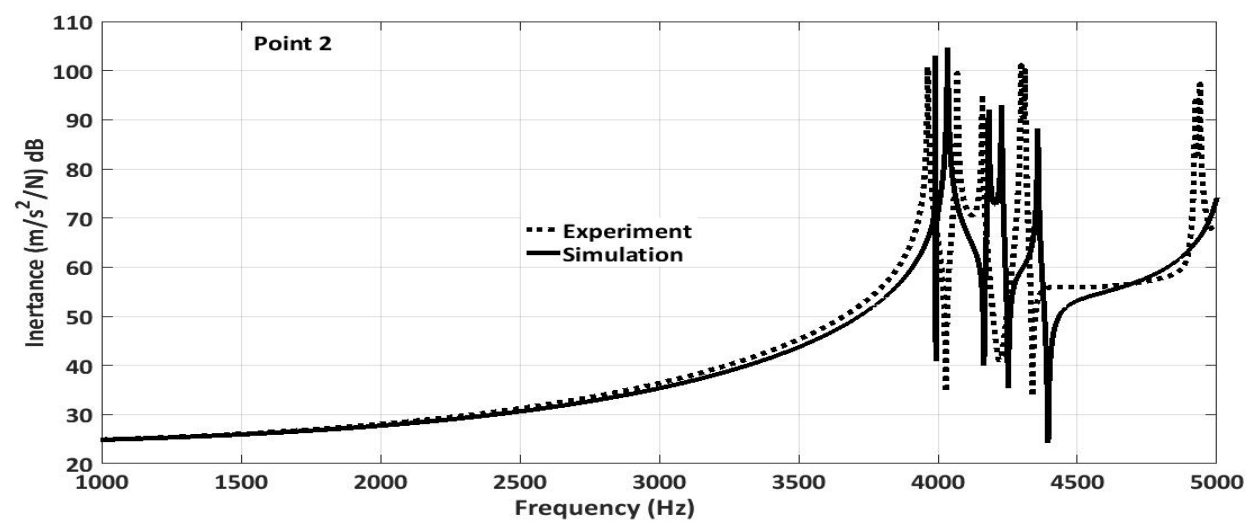

Figure 3: Comparison of FRFs of cylindrical cup between current FE results and experimental results at Point-2. 
The current simulation methodology can be considered as a reasonable rep-
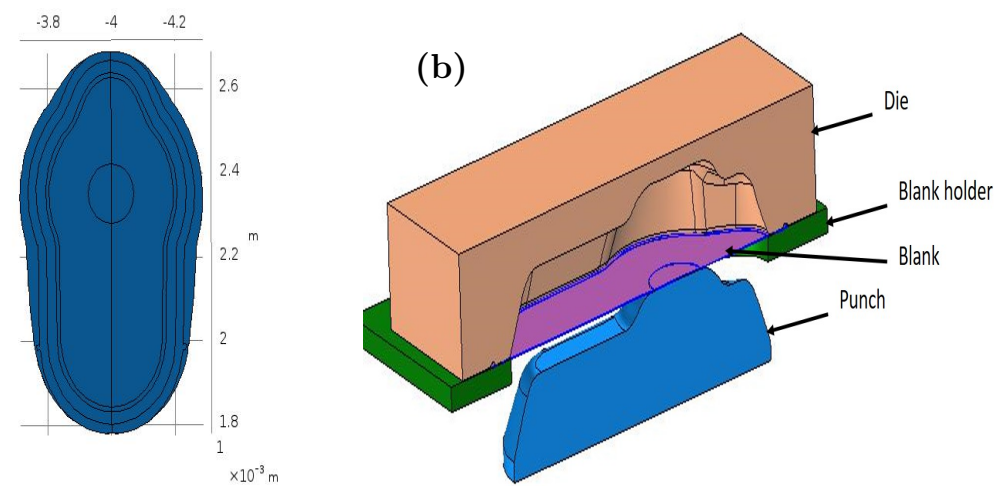

Figure 4: The simulation model set-up of a) blank b) die, punch and blank holder plate.

The blank for manufacturing an oil pan look-alike component is shown in Figure 4a. The length, width, and depth of the component are $852 \mathrm{~mm}, 458 \mathrm{~mm}$, and $142 \mathrm{~mm}$ respectively. The blank material has a thickness of $1.5 \mathrm{~mm}$, and 
is made of IS 513 CR3 grade. The density, modulus of elasticity, and Poisson ratio of the blank material are $7850 \mathrm{~kg} / \mathrm{m}^{3}, 2.16 \times 10^{5} \mathrm{MPa}$, and 0.3 respectively. The mechanical properties are obtained from tensile testing of a specimen using ASTM standard [24] and are rounded off to the nearest values. The punch, die and blank holder plate is made of medium carbon steel (EN8), considering the ease of machinability of the material. As the structural rigidity of punch, blank, and the blank holder is very high, these components are considered as sources and are modelled as rigid components while creating contact pairs in the deep drawing analysis. The plasticity effect of the blank is modelled, as explained in the previous section, and it is identified as a destination object in the contact pair.

The deep drawing simulation model set-up is shown in Figure 4b. Only one half of the model is considered, to take advantage of symmetry about the XZ plane. The blank is meshed with two layers of hexahedral (brick) elements in the thickness direction and with a maximum element length of $3 \mathrm{~mm}$ on the rest of the faces. The punch, blank holder, and die are meshed with tetrahedral elements. The model consists of 15154 elements, and a HPC server is used for the calculations, which took 19 hours. The Von-Mises yield criterion along with isotropic hardening is chosen, to analyse the plasticity effects of the blank. The solver and other related settings are as described in Section 2.2. The blank holder force (BHF) and friction coefficient $(\mu)$ are varied at two levels: case-i) BHF $300 \mathrm{kN}$ with a friction coefficient $(\mu) 0.1$ and case-ii) BHF $400 \mathrm{kN}$ with a friction coefficient $(\mu)$ 0.2. These process parameters are based on the research work of Mouatassim et.al. [25], as the oil pan's dimensions are very similar. The formed components are shown in Figure 5. Both the process-parameter configurations are formed to the complete depth and are free of fractures. The geometric profile comparison is carried out using Geomagic Design-X [26], by overlaying the geometries obtained from the results of the forming simulations, as shown in Figure 6. The geometry profile deviation is considered positive when it occurs on the positive normal side of the reference component and negative if it is on the opposite side. The formed part using process parameters of case-i 
is considered as reference geometry. A maximum profile deviation of $2.2 \mathrm{~mm}$

on the positive side and a $2.3 \mathrm{~mm}$ deviation on the negative side is observed. The histogram on the right-hand side of Figure 6 shows the distribution of the geometry profile variation. The skewed distribution shows about $45.8 \%$ and $32.5 \%$ of the total surface area has a deviation of up to $0.8 \mathrm{~mm}$ on the positive and negative sides, respectively.
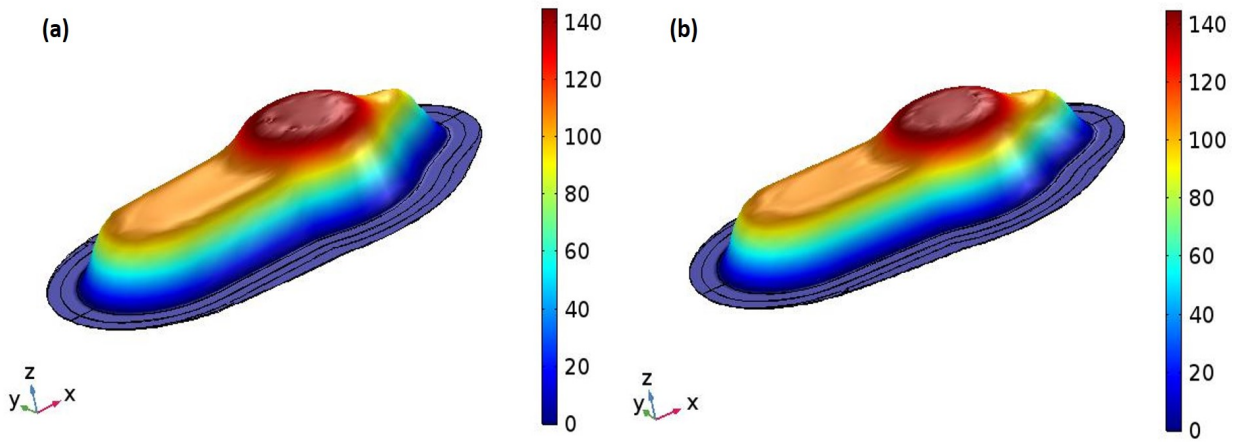

Figure 5: Formed component geometry after deep drawing simulation a) case-i b) case-ii respectively.
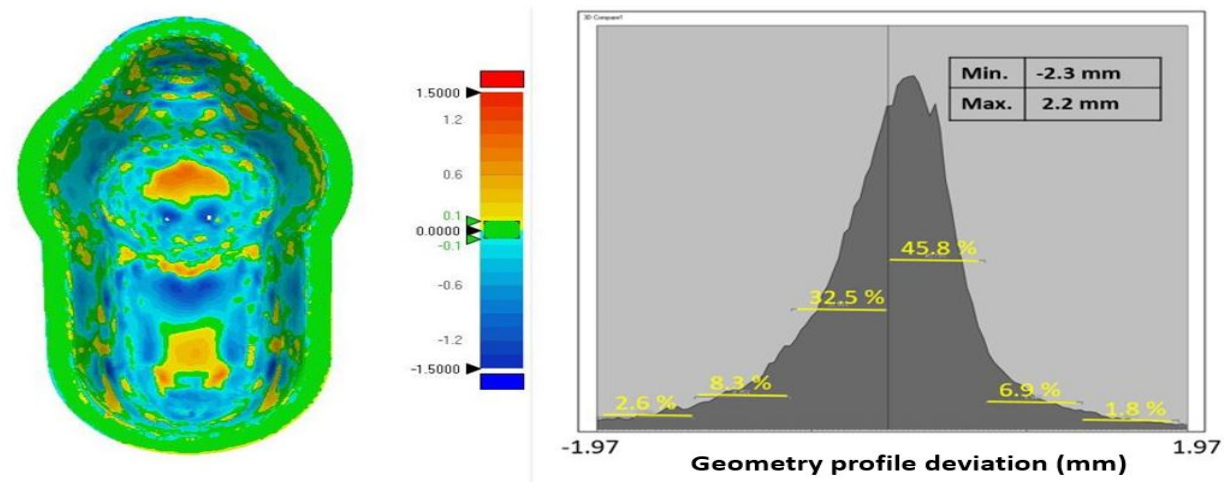

Figure 6: Comparison of top surface profile deviation between case-i \& case-ii simulation results.

Figure 7 shows the thickness distribution of the component after the completion of the deep drawing process. It is observed that the thickening and the thinning phenomenon (an increase of thickness and reduction of thickness when compared to nominal thickness) happens at different regions of the components. 


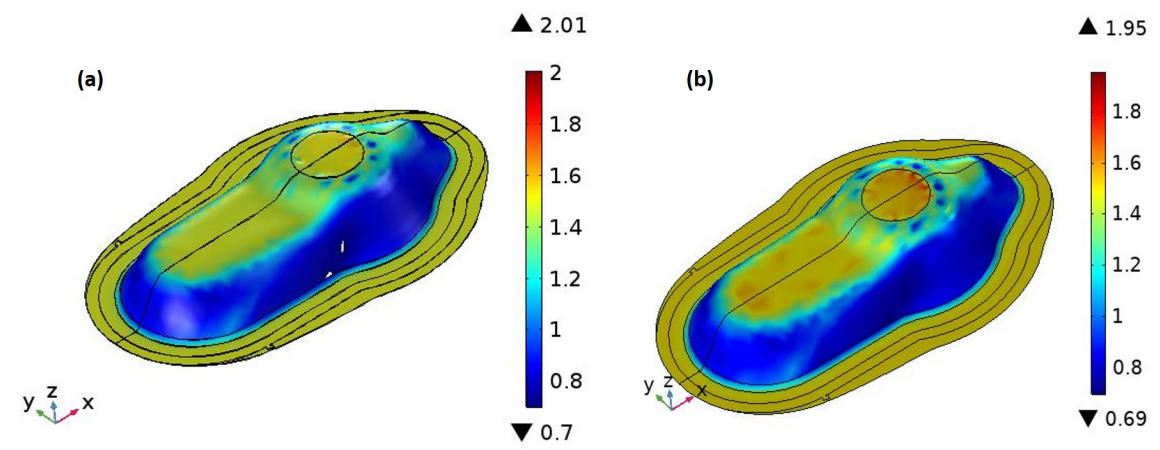

Figure 7: Thickness distribution in formed component a) case-i b) case-ii respectively.

The maximum and minimum thicknesses for case-i is respectively $2.01 \mathrm{~mm}$ and

$0.7 \mathrm{~mm}$ while that for case-ii are $1.95 \mathrm{~mm}$ and $0.69 \mathrm{~mm}$. Also, the thickness distribution pattern is different between both cases. Hence, it can be concluded that considerable changes in the geometric profile and thickness distribution pattern occurred between the two simulation cases. In the next section, the influence of geometric profile and thickness distribution variations on the vibroacoustic behaviour of the component is presented.

\section{Vibro-Acoustic behaviour}

The vibro-acoustic analysis of the two formed-geometries of the previous section is carried. Section 3.1 presents the theory of vibro-acoustics very briefly. The comparison of vibration response behaviour, acoustic directivity patterns 245 and sound power levels between the two formed-geometries is presented in Section 3.2 .

\subsection{Theoretical formulation}

The equation of motion for a multi DOF linear-elastic mechanical/structural dynamic system can be written as [27]:

$$
[\mathbf{M}]\{\ddot{x}\}+[\mathbf{C}]\{\dot{x}\}+[\mathbf{K}]\{x\}=\{f\},
$$



and the global stiffness matrix of the component, respectively. The force vector is defined as $\{f\}$, and it is used for exciting the system. The response of the The response of the equation(7) is obtained using modal decomposition, assuming modal response $y(t)=\mathbf{Y} \exp (i \omega t)$ and modal forces $q(t)=\mathbf{Q} \exp (i \omega t)$ in

modal domain. The physical response of the system is obtained using a modal matrix $[\mathbf{P}]$ as explained [28].

$$
\mathbf{X}=\mathbf{P} \mathbf{Y}
$$

In the present work, finite elemental formulations are used for computing the global mass, damping and stiffness matrices. The elemental matrices, as explained in reference [29], are assembled and transformed to a global reference system.

The acoustic pressure variation is assumed to be harmonic. Hence, the wave equation becomes:

$$
\nabla \cdot\left(-\frac{1}{\rho_{0}} \nabla p\right)-\frac{\omega^{2} p}{\rho_{0} c^{2}}=Q_{m},
$$

where $\rho_{0}, c, Q_{m}$ are the density, speed of sound, and monopole domain source, respectively. The air adjacent to the elastic structure should move with the same velocity as the structure.

The structural displacements are obtained by using Eqn. (8) and the acoustic response of the structure is computed by solving the equation (9) using appropriate structural and acoustic boundary conditions. In this work, weakly coupled system behaviour is considered as the acoustic pressure does not influence the structural displacement state.

\subsection{Oil pan simulations results}

In this section, the formed-geometries obtained from the deep drawing simulation results of both configurations are analysed to study their vibro-acoustic behaviour. The comparison of eigenfrequencies, mode shapes, vibration, and acoustic responses between the two geometries is presented. 


\subsubsection{Vibration response}

In this section, the impact of the geometric profile and thickness distribution variations on the vibro-acoustic response is presented. Table 3 shows a comparison of the first six natural frequencies of the component in the free-free boundary conditions between the two different deep drawing simulation results. A difference of about $2.5 \%$ in the natural frequencies and considerable changes in the mode shape behaviour is observed. To quantify the mode shape changes, the modal assurance criterion (MAC), as defined by Allemang et al. [30] is computed for both the configurations.

\begin{tabular}{cccc}
\hline Sl.No. & Case-i & Case-ii & \% difference \\
\hline 1 & 109.8 & 107.3 & 2.3 \\
2 & 138.8 & 135.6 & 2.3 \\
3 & 216.6 & 211.9 & 2.2 \\
4 & 252.2 & 246.8 & 2.1 \\
5 & 267.2 & 272.7 & -2.1 \\
6 & 269.1 & 275.8 & -2.5 \\
\hline
\end{tabular}

Table 3: Comparison of FE natural frequencies $(\mathrm{Hz})$ of the component in free-free boundary conditions between two deep drawing simulation cases.

Figure 8 shows a comparison of MAC results between the simulation cases. The diagonal terms in the MAC matrix are closer to unity for the low frequency modes, i.e. up to first 20 modes and hence it can be concluded that the correlation is good. However, the presence of off-diagonal values, especially at higher frequencies, indicates that mode shape correlation is not good. The similarity between the adjacent mode shapes increases with the increase in frequency, thus leading to off-diagonal values in the MAC matrix.

The comparison of FRFs is carried out to understand the effect of these changes on the vibrational responses. Figure 9 shows driving point responses (DPR) of inertance at four locations. The comparison of the sum of FRF responses of all the points and individual measurement location response of the 


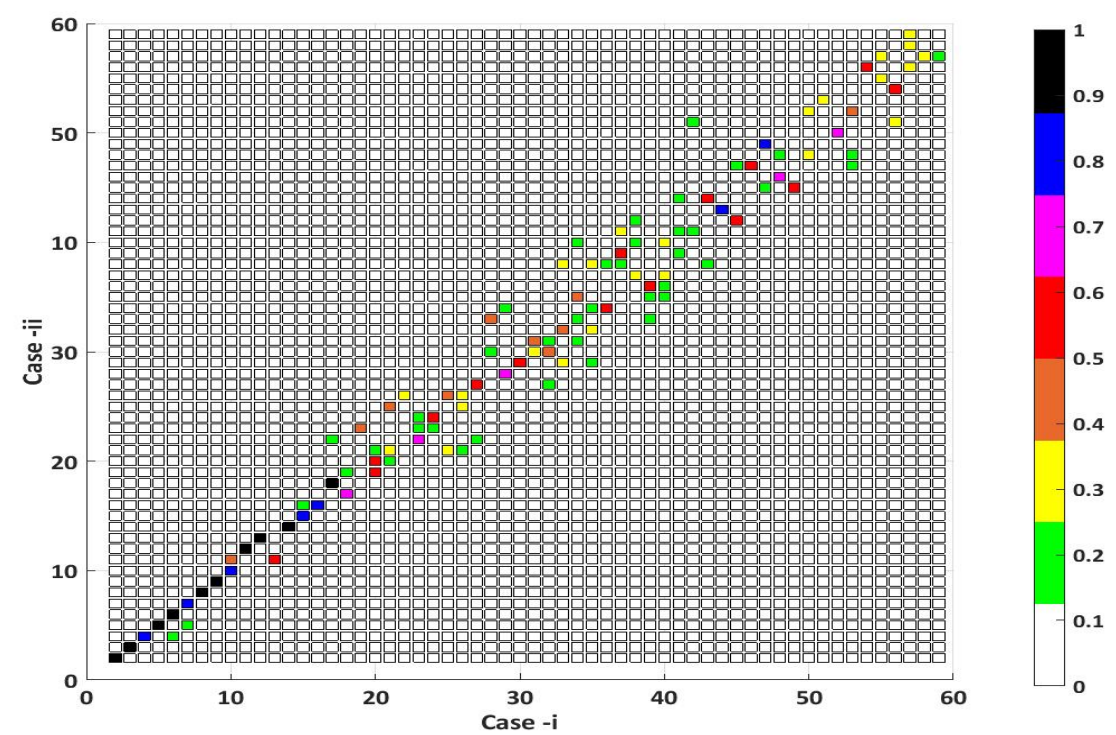

Figure 8: Comparison of MAC results between two simulation results : case-i \& case-ii in free-free boundary conditions.
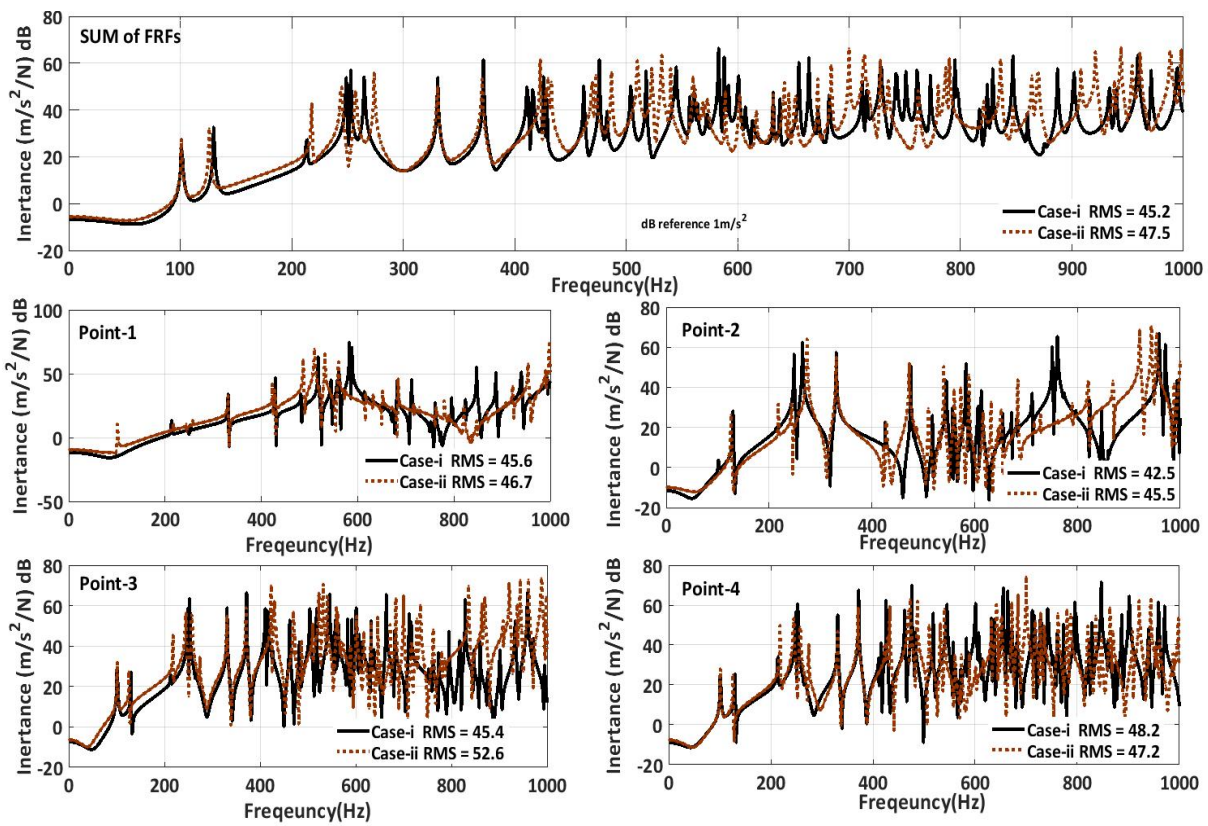

Figure 9: Comparison of vibration response at different points (shown in Fiugre 10) of geometries obtained from case-i \& case-ii simulation results. 
four points between the two BHF configurations is presented. The component is excited at five different points P1, P2, P3, P4 \& P5 in the normal direction to the surface, to obtain DPR, as shown in Figure 10. In the case of sum of FRF, root mean square(RMS) difference of $2.3 \mathrm{~dB}$ and at least $1 \mathrm{~dB}$ difference at other points is observed. Hence, it can be concluded from the results that vibration responses are different with respect to both frequency and amplitude levels.

\subsubsection{Acoustic response}

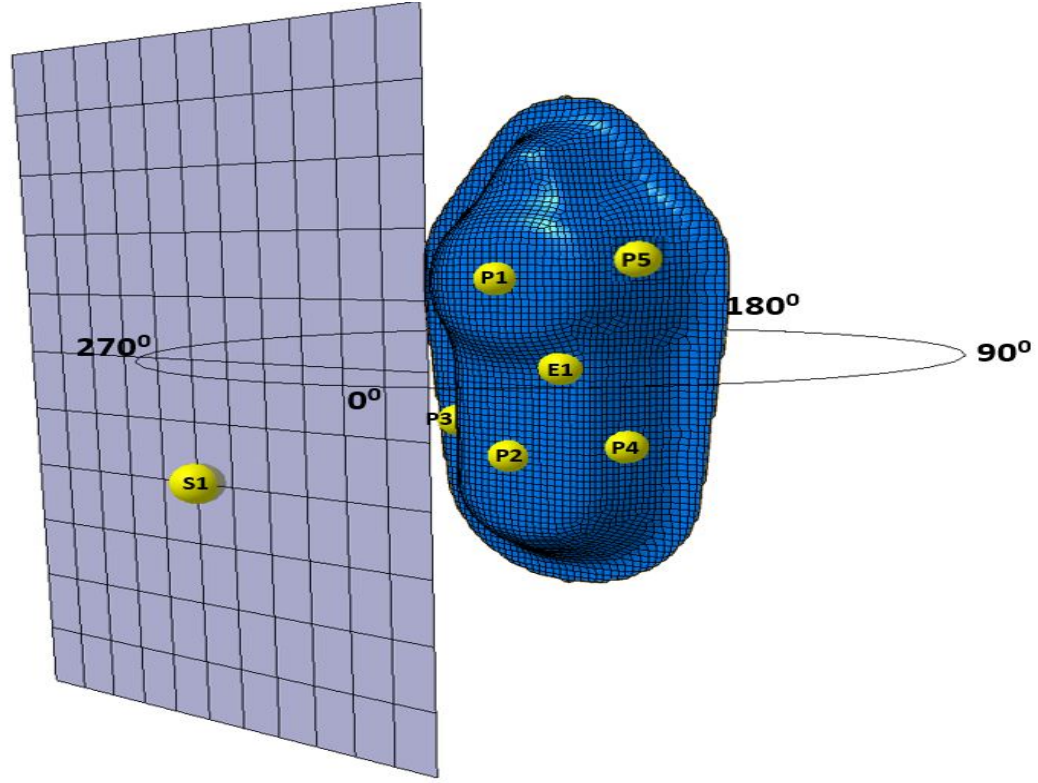

Figure 10: Representation of component acoustic mesh, field mesh and directivity pattern.

The acoustic analysis of the geometries obtained from two simulation cases is carried out to compare the radiated noise levels. The component is analysed using the boundary element method (BEM)[31] to predict the sound pressure levels using LMS Virtual Lab [32]. The BEM mesh of the component consists of six elements per wavelength until the frequency of $5000 \mathrm{~Hz}$, to obtain accurate results. The part is excited (at point E1 in the normal direction, as shown in Figure 10) using experimentally-obtained shaker force, to predict the vibroacoustic response. The acoustic response is computed between 1-1000 Hz with 
a $1 \mathrm{~Hz}$ frequency resolution. A planar field mesh $(0.95 \mathrm{~m} \times 0.65 \mathrm{~m})$ at a distance of $0.5 \mathrm{~m}$ from the centre of the component and a directivity mesh, as shown in Figure 10, are created. Figure 11 shows sound pressure levels predicted at field mesh point (S1) for both cases. The SPL values are not very different until the frequency of $400 \mathrm{~Hz}$, as shown in the figure. However, both amplitude and frequency variations are observed in the high frequency range. Figure 12 shows

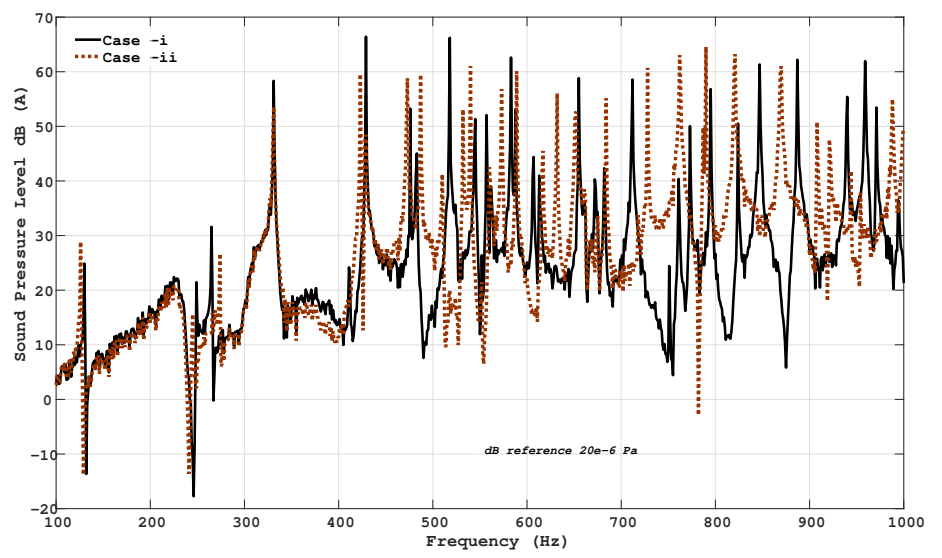

Figure 11: Comparison of sound pressure levels at field mesh point (S1) between case-i \& case-ii simulation results.

the noise directivity comparison between the two simulated cases. The radiation patterns differ between the two cases and are more prominent at higher frequencies, as the mode shapes are increasingly different.

Figure 13 shows a comparison of sound power levels between the two cases where the RMS acoustic power is varied by $1.4 \mathrm{~dB}$. Although there is a reasonable match between the results at lower frequencies, variation is observed at higher frequencies. Hence, it can be concluded from the above simulations that $\mathrm{BHF}$ and friction coefficient have a significant influence on the geometric profile and thickness distributions that lead to differences in vibro-acoustic properties. The geometric differences although are not very significant w.r.t. dimensional accuracy, have a high influence on vibro-acoustic properties. The simulation findings confirm the sensitivity of the process parameters of deep drawing to 

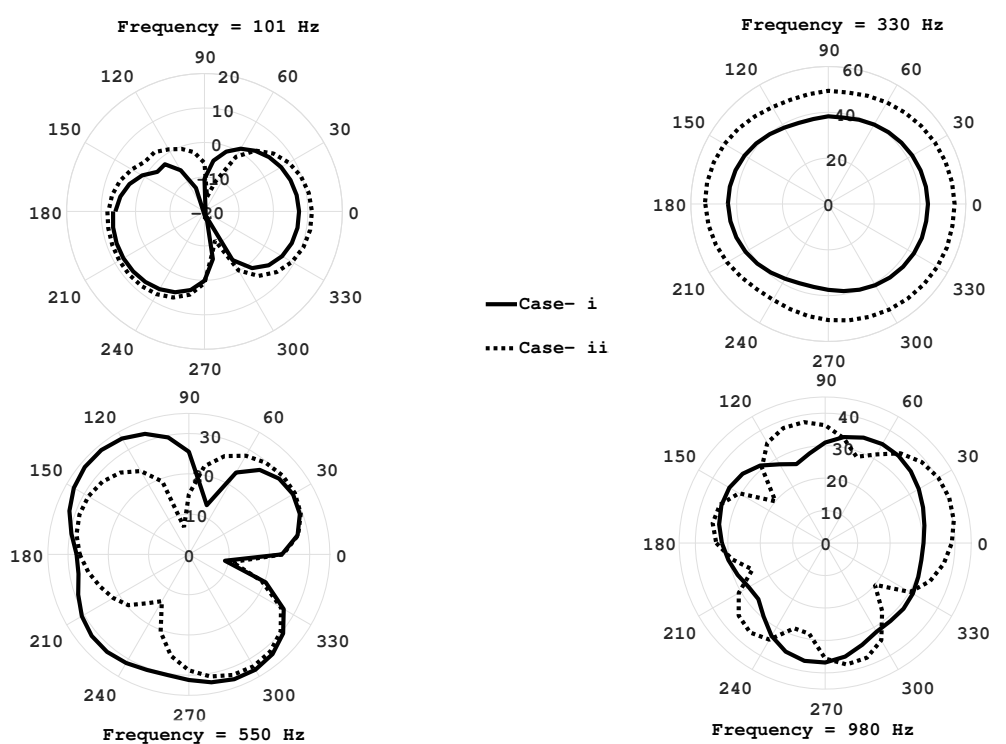

Figure 12: Comparison of noise radiation patterns between the two simulation cases at different frequencies.

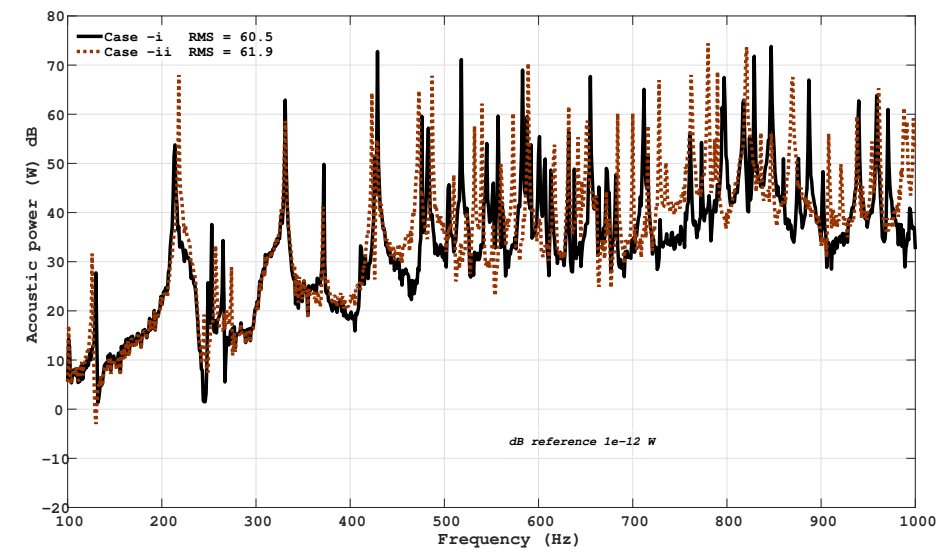

Figure 13: Comparison of sound power levels between case-i \& case-ii simulation results.

vibro-acoustic performance of the tested two sets of physical prototypes, which will be discussed in the subsequent sections.

\subsubsection{The impact of stiffness and mass distribution changes}

The process parameter changes lead to different geometric profile and thickness distribution patterns between the two deep drawing simulation studies. 

changes the stiffness and mass matrices in the equation (11) that eventually results in different responses. These variations also cause significant changes in eigenvectors of the system and thereby altering the modal response and finally impacting the physical response, although sometimes corresponding natural frequency shifts are negligible.

\section{Component manufacturing and dimensional measurements}

Two physical components are manufactured through the deep drawing process. The blank material for both the components is selected from the initial part of a coil, and all the blanks are cut along the axial direction. This ensures the least variation in the blank material properties. The thickness and flatness measurements at several points of these blanks are carried out and found that these variations are negligible. The lubrication of all the contact pairs is carried out using semi-solid lubricants. A hydraulic press, model HD 3146 from BEMCO Hydraulics with 315 ton capacity is used for manufacturing components. 350 Two components are manufactured, with about a variation of $25 \% \mathrm{BHF}$, through deep drawing process and these components are subsequently tested to evaluate their vibro-acoustic behaviour. The manufactured parts are visually inspected and are found to be devoid of any cracks. These components are scanned using a white-light scanner [33] to generate cloud point data. Figure 14 shows the comparison of geometry and thickness distribution between the physical part (manufactured with $300 \mathrm{kN} \mathrm{BHF}$ ) and the original CAD component.

A maximum of $5 \mathrm{~mm}$ deviation in the geometry profile is observed at the studied cross-sections. The maximum and minimum thicknesses found at these two sections are $1.1 \mathrm{~mm}$ and $1.8 \mathrm{~mm}$ respectively. The next section presents a comparison of vibro-acoustic measurement results of the manufactured components. The geometric profile deviation amounts only about $3.5 \%$ of the total depth of the component and hence are referred to as small geometric variations throughout the present work. 


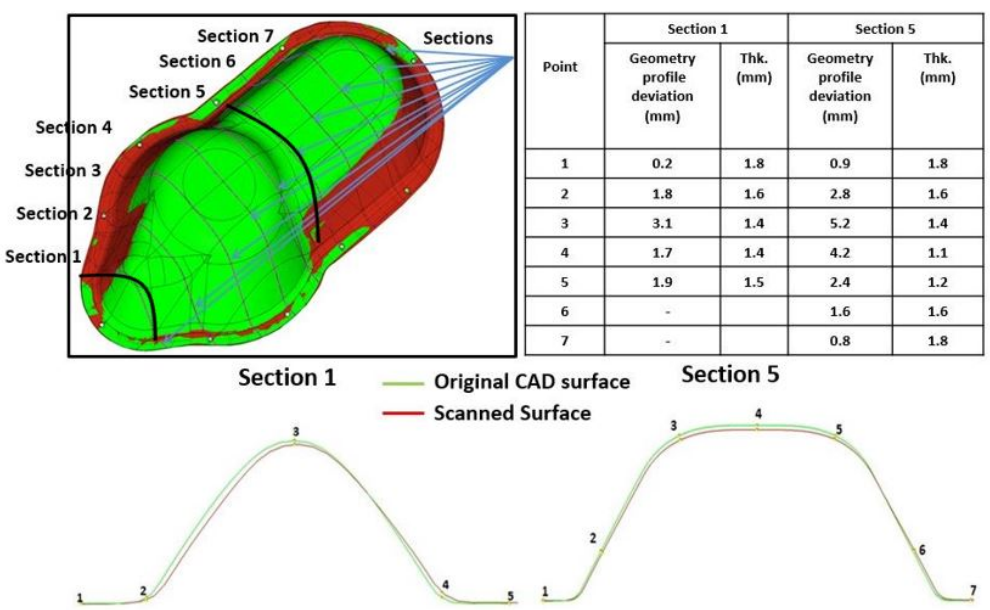

Figure 14: Profile deviation and thickness comparison of the top surface geometry between the original CAD component and actual manufactured component.

\section{Experimental measurements of vibro-acoustic properties}

This section presents the physical measurement results of oil pans that are manufactured using two different process parameters corresponding to the forming simulations. The impact of small geometrical changes on the vibro-acoustic performance of the components is presented. Section 5.1 presents experimental modal testing results of these two oil pans. The acoustic performance of the components is described in the subsequent section.

\subsection{Modal testing}

The modal testing of the component is carried out in free-free boundary conditions. Thus, the part is suspended using four sets of bungee cords, as shown in Figure 15. A roving hammer technique is chosen for carrying out modal tests. The five response locations, as shown in the figure, are selected such that they are not node points for the frequency range of interest.

Modal testing includes 102 impact locations on the test object to be able to avoid any spatial aliasing of modes in the frequency range of interest. The data acquisition is carried out using LMS SCADAS SCM-05 [34] while LMS 


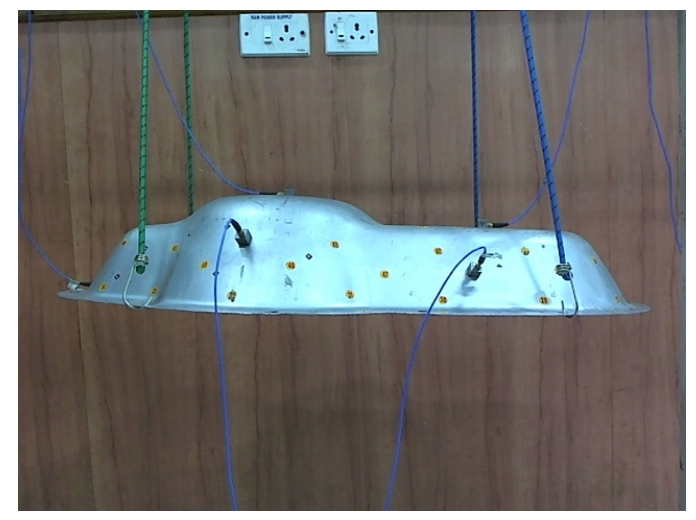

Figure 15: Test set-up of modal testing of component in free-free conditions.

380 each response location is obtained by carrying out ten averages. The sampling frequency used for acquiring the data is $2048 \mathrm{~Hz}$, along with $0.25 \mathrm{~Hz}$ frequency resolution. The relatively longer acquisition time period (4 seconds) ensured the complete decay of the response signal. A force-exponential window is apfundamental frequency is varied by about $7 \%$ between the two components and this difference increases up to $20 \%$ at sixth mode. The experimental modal test results show that mode shapes varied significantly between the components. The data presented in the table consider frequency variation between the compo395 nents without indicating the possible amplitude level differences. To investigate the latter, frequency response function comparison is carried out. To this end, the component's behaviour is represented using a sum of FRFs, (by squaring the magnitudes at each frequency and then summing up for all FRFs) of the components. 


\begin{tabular}{ccc}
\hline Comp-1 & Comp-2 & Difference (\%) \\
\hline 89 & 83 & 6.7 \\
111 & 107 & 3.6 \\
247 & 242 & 2.0 \\
260 & 252 & 3.1 \\
317 & 329 & -3.7 \\
364 & 439 & -20.6 \\
\hline
\end{tabular}

Table 4: Comparison of natural frequencies $(\mathrm{Hz})$ of both the components in free-free boundary conditions

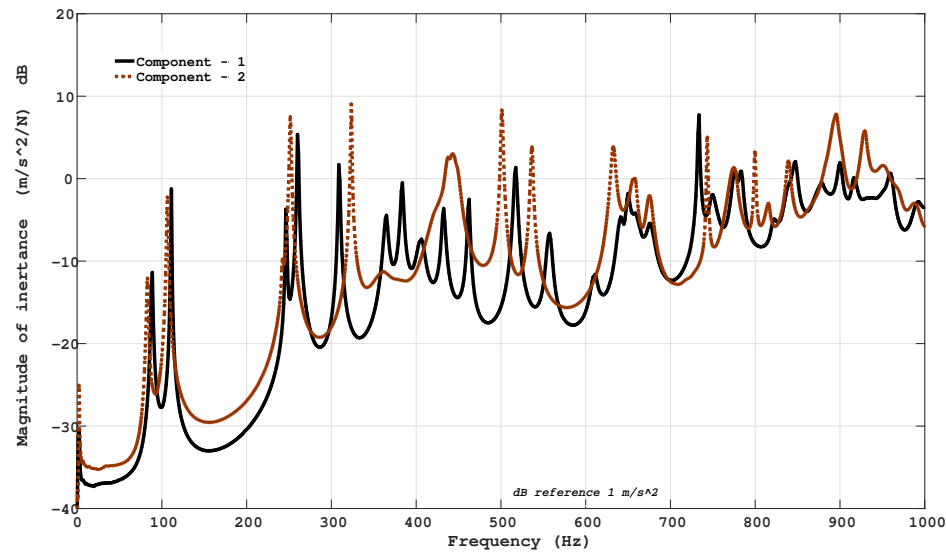

Figure 16: Comparison of sum of FRFs between the components in free-free boundary conditions.

400

The sum of FRF curves of the components in free-free boundary conditions for the frequency range of $0-1000 \mathrm{~Hz}$, is shown in Figure 16. It can be seen from the results that not only the eigenfrequencies but also the amplitude levels vary between the components. These differences are more pronounced at higher frequencies, as observed from the results. Hence, it can be concluded that small geometric changes that occur during the manufacturing process result in different vibrational properties of the component. 


\subsection{Acoustic testing}

In order to understand the effect of small geometric changes of components on the radiated noise, acoustic testing is carried out. The typical acoustic test

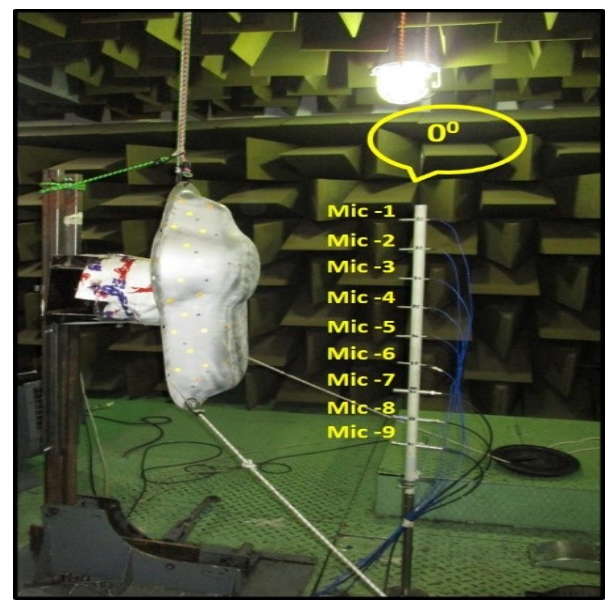

Figure 17: Acoustic test set-up of a component

\subsubsection{Acoustic transfer functions}

The component is excited using an impact hammer at the accelerometer locations of the modal testing, to obtain noise transfer functions $(p / F)$, to all the nine microphones at a given array angle. To understand the directivity pattern, acoustic measurements are carried out at the remaining angles. A 
sum of FRFs of all microphones for all excitation locations and at all angles is considered as the noise-emitting characteristic representation of the component. Figure 19 shows that the frequency and amplitude levels are different between the components. Similarly, variation at higher frequencies i.e. above $500 \mathrm{~Hz}$ is even higher. Figure 18 shows the comparison of the directivity pattern at different frequencies between the two components. The directivity patterns are somewhat similar in the lower frequencies and however are different at higher frequencies. It can be concluded that variations observed at vibration levels manifest in the acoustic impact testing results at this particular microphone location.
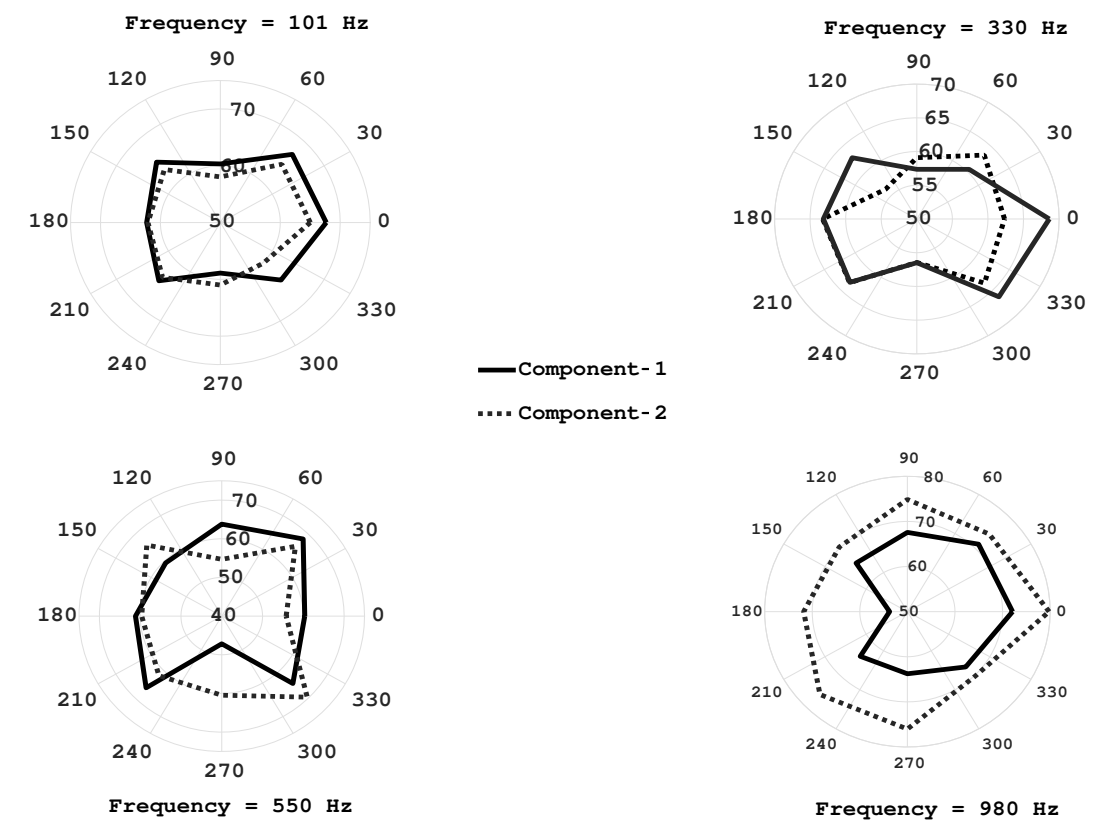

Figure 18: Comparison of noise radiation patterns between the two physical components at different frequencies.

\subsubsection{Acoustic response}

Acoustic response measurements of components are carried out using a modal shaker. As the excitation is free from any external noise and it is highly controllable, shaker excitation is more reliable when compared to impact excita- 


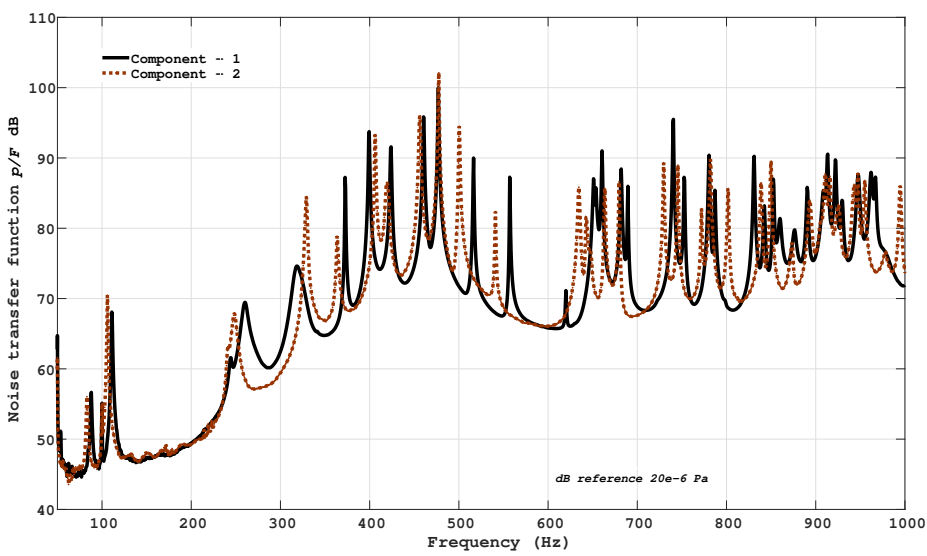

Figure 19: Comparison of acoustic response of impact testing in free-free boundary conditions.

tion. However, in such a testing, shaker noise itself could be a concern. Hence, the outer casing of the shaker is wrapped with a noise insulation material. The comparison of ambient noise, shaker noise, and component noise when excited using a shaker is shown in Figure 20. The shaker noise is highly predominant till the frequency of $315 \mathrm{~Hz}$ and hence measurements below this frequency can not be used for drawing any conclusions. However, at least about $10 \mathrm{~dB}(\mathrm{~A})$ difference in noise levels above $315 \mathrm{~Hz}$ frequency is observed between the shaker noise and noise radiated by the component. In the entire noise measuring frequency spectrum range i.e. between $0-4096 \mathrm{~Hz}$, it is found out that there is about 30 $\mathrm{dB}(\mathrm{A})$ difference in sound pressure levels (SPL) between the noise emitted by the component and the shaker noise. Hence, the noise generated by the shaker can be considered negligible. The SPL of components measured using shaker excitation at microphone- 5 in $0^{\circ}$ array position is shown in Figure 21.

The variation is somewhat moderate up to frequency range of $500 \mathrm{~Hz}$. In contrast, after $500 \mathrm{~Hz}$ it becomes much higher, as observed with the acoustic response of impact testing and modal testing results. A-weighted RMS dB 455 value is considered as a representative metric of the radiated noise of each component. The highest and lowest radiated noise levels are $66.2 \mathrm{~dB}(\mathrm{~A})$ and 63.7 $\mathrm{dB}(\mathrm{A})$ corresponding to component-1 and component-2, respectively. Hence, it 


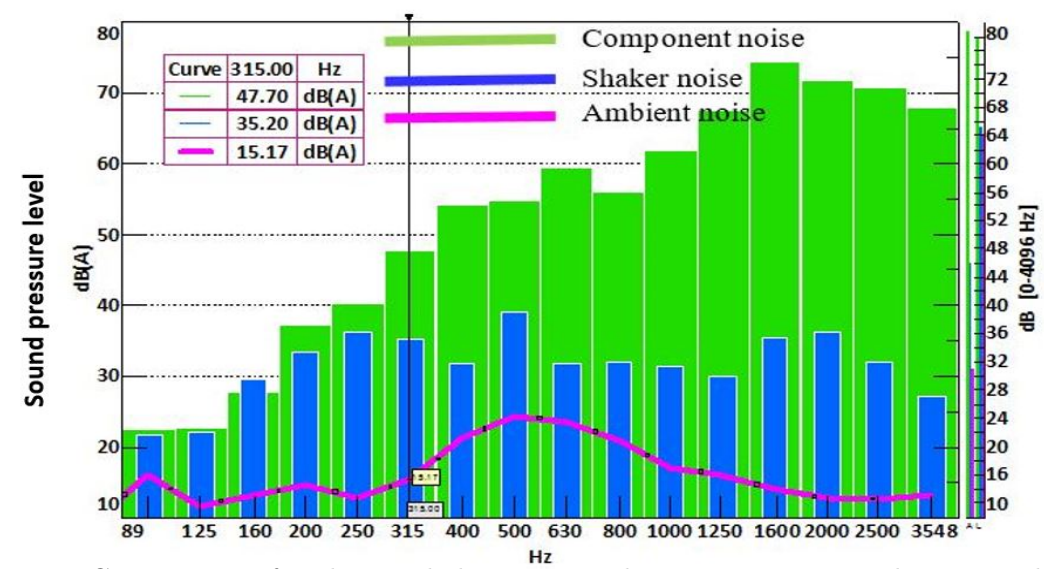

Figure 20: Comparison of ambient, shaker noise and component noise when excited by the shaker.

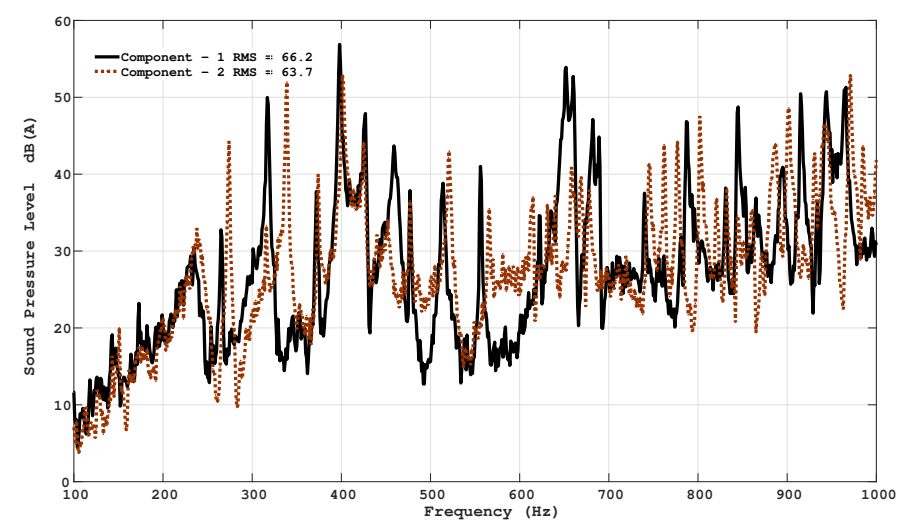

Figure 21: Comparison of sound pressure levels (SPL) of components due to shaker excitation.

can be stated that there is a $2.5 \mathrm{~dB}(\mathrm{~A})$ difference in SPL values of the tested components.

\subsubsection{Acoustic intensity (using P-u probe) results}

In the previous sections, it is shown that the acoustic noise transfer functions and the radiated noise of the components varied significantly between the components. However, the differences in vibro-acoustic behaviour of the components cannot be categorically ascertained without evaluating sound power radiated by them. A $P$ - $u$ probe that measures acoustic pressure and particle velocity simultaneously is used to measure sound intensity. The sound power is 
estimated through ISO 9614 using the measured sound intensity. The component is excited through a modal shaker, and the noise measurements are carried out using a $P-u$ probe. The fundamental principle of this probe and comparison with the conventional sound intensity technique is explained by Jacobsen et al. [36]. The average sound intensity contour plots in the frequency range of $50-1000 \mathrm{~Hz}$ of the components is shown in Figure 22. The contour plot results show that component-1 has somewhat higher sound intensity levels than the other component. This phenomenon can be attributed to the dynamic behaviour difference between the two components. The frequency distribution of the components in the frequency range $(50-1000 \mathrm{~Hz})$ is different. The vibration FRF amplitude levels of component-2 are lower, as shown in Figure 16, since the deep drawing manufacturing process altered the mode shapes differently between these two components. The vibrational mode shape changes manifest themselves in different radiated noise directivity patterns. Hence, the intensity levels are different between these two components.
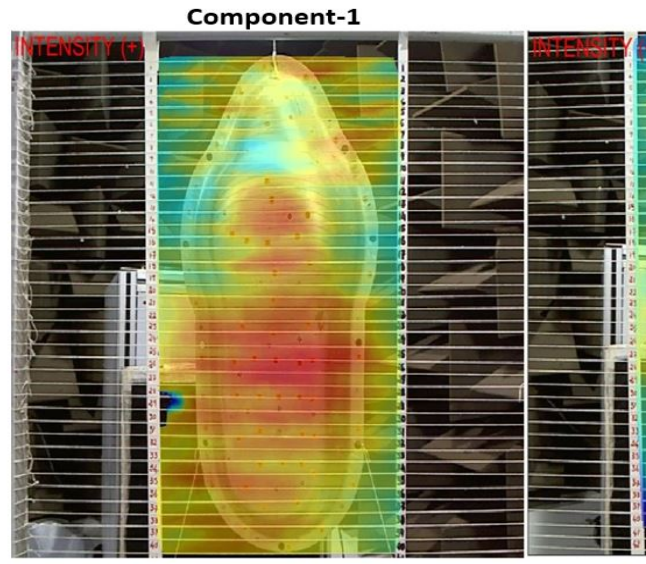

Component-2

Figure 22: Comparison of sound intensity contour plots (in 0-1000 Hz. frequency range) of the components.

The radiated sound power levels of component-1 and component-2 are 65.4 $\mathrm{dB}(\mathrm{A})$ and $63.3 \mathrm{~dB}(\mathrm{~A})$ respectively and thus about a $2 \mathrm{~dB}(\mathrm{~A})$ sound power difference between the components. Hence, it can be concluded that the above vibro-acoustic measurement results indicate that there is a considerable varia- 
tion between the components, although the dimensional changes are not significantly different. The difference in the vibro-acoustic properties of the components can be thus attributed to the small changes in process parameters that occurred during the manufacturing process.

\section{Concluding remarks}

This paper presents an attempt to relate deep drawing process parameter changes to vibro-acoustic behaviour. Most researchers in the past often have limited their studies to relate process parameter changes to dimensional accuracy achievement. The forming simulation of an oil pan look-alike component is carried out after validating the simulation methodology. Two simulation cases are analysed using a small perturbation of baseline process parameters and the vibro-acoustic performance comparison is carried out. Although geometrical profile and thickness variations are very small, these changes are significant for the vibro-acoustic property behavior and affect sound power levels by $1.4 \mathrm{~dB}(\mathrm{~A})$. Two physical prototypes, with about $25 \%$ variation in BHF, are manufactured through the deep drawing process. The maximum profile deviation observed is $5 \mathrm{~mm}$ when compared to the nominal CAD surface. The experimental modal testing results indicate that natural frequencies vary to a considerable degree in free-free boundary conditions; the variation between the components increases at higher frequencies. The acoustic results of these components obtained using an impact hammer, a modal shaker and a $P$ - $u$ probe, have significant variation. It is shown that radiated sound power levels of these components vary by about $2 \mathrm{~dB}(\mathrm{~A})$ in the $0-1000 \mathrm{~Hz}$. frequency range. Hence, from the present study results, it can be concluded that a holistic approach - starting from design, the inclusion of manufacturing effects and controlling variability - is to be adopted to obtain robust vibro-acoustic performance of components/systems. The prevalent method of improving only the nominal design may not yield superior results when compared to the former approach. 


\section{References}

515 [1] V.A.Zharkov, Theory and Practice of Deep Drawing, Mechanical Engineering Publications, 1995.

[2] Body Systems Analysis Task Force, Stamping process variation: An analysis of stamping process capability and implications for design, die tryout and process control, Tech. rep., Auto/Steel Partnership Program, 2000 Town Center - Suite 320, Southfield, MI 48075-1123 (1999).

[3] W.Hancock, M.Zayko, M.Autio, D.Ponagajba, Analysis of components of variation in automotive stamping processes, Quality Engineering 10(1) (1997) 115-124.

[4] J. F.Siekirk, Process variable effects on sheet metal quality, Journal of Applied Metalworking 4 (1986) 262-269.

[5] S.Yossifon, K.Sweeney, M. Ahmetoglu, T.Altan, On the acceptable blankholder force range in the deep-drawing process, Journal of Materials Processing Technology 33 (1992) 175-194.

[6] K.Siegert, M. Ziegler, S.Wagner, Closed loop control of the friction force. Deep drawing process, Journal of Materials Processing Technology 71 (1997) 126-133.

[7] W.J.Thomas, Product, tool, and process design methodology for deep drawing and stamping of sheet metal parts, Ph.D. thesis, The Ohio State University (1999).

[8] M. Karima, V. Donatelli, Understanding blank holder effect on formability of sheet metal stampings, SAE Annual Congress and Exposition, Detroit, Michigan, 1989, p. 1-10.

[9] B. Voss, Galling wear detection and measurement in sheet metal forming, Ph.D. thesis, Australian National University (2018). 
[10] C. Koh, J. Shi, J. Black, J. Ni, Tonnage signature attribute analysis for stamping process, NAMRI/SME Trans 24 (1996) 193-198.

[11] A. Prior, Applications of implicit and explicit finite element techniques to metal forming, Journal of Materials Processing Technology 45 (1994) 649-656.

[12] S. W. Lee, D. Yang, An assessment of numerical parameters influencing springback in explicit finite element analysis of sheet metal forming process, Journal of Materials Processing Technology 80-81 (1998) 60-67.

[13] S. C. Tang, Trends on simulation of sheet metal forming processes, SAE 2000 World Congress, Detroit, Michigan, 2002.

[14] R.Echempati, V. M. S. Dev, Spring back studies in aluminum alloys, SAE 2002 World Congress, 2002.

[15] M.S.Kompella, R.J.Bernhard, Measurement of the statistical variation of structural-acoustic characteristics of automotive vehicles, SAE 931272 (1993) 41-46.

[16] E.Hills, B.R.Mace, N.S.Ferguson, Acoustic response variability in automotive vehicles, Journal of Sound and Vibration 321 (2009) 286-304.

[17] V. M. S. Dev, S. Angadi, S. Roy, Forming and modal analysis of sheet metal oil pan, SAE 2002 World Congress, 2002.

[18] V. K. Balla, L. Coox, E. Deckers, B. Plyumers, W. Desmet, K. Marudachalam, Obtaining manufactured geometries of deep-drawn components through a model updating procedure using geometric shape parameters, Mechanical Systems and Signal Processing 98 (2018) 382-401.

[19] V. K. Balla, L. Coox, E. Deckers, F. Greco, B. Plyumers, W. Desmet, A study of vibro-acoustic behaviour variation of thin sheet metal components manufactured through deep drawing process, Applied Acoustics 153 (2019) $110-1261$. 
[20] R. Kaiser, Technology assessment of automotive aplications of metal, Tech. rep., Argos Associates, Inc, 12 Glengarry, Winchester, MA (1980).

[21] COMSOL Multi Physics analysis User's Manual, Version 5.3, Structural mechanics module (2017).

[22] F. Greco, E. Deckers, J. Stroobants, S. Van Poppel, K. Linck, W. Desmet, Finite element simulation of the dynamic behaviour of deep drawn components with accurate thickness description, Finite Elements in Analysis and Design 138 (2018) 12-20.

[23] P.Wriggers, T.Vu Van, E.Stein, Finite element formulation of large deformation impact-contact problems with friction, Computers \& Structures 37 (1990) 319-331.

[24] ASTM E8 / E8M-11, Standard Test Methods for Tension Testing of Metallic Materials, Tech. rep., ASTM International, West Conshohocken, PA (2011).

[25] M. E. Mouatassim, J. Jameux, B. Thomas, F. Mehrez, G. Milcent, The simulation of multi-operation deep-drawing process at renault with pam stamp, Journal of Materials Processing Technology 45 (1994) 317-322.

[26] Geomagic Design X, Geomagic Design X 2019 Software Manual (2019).

${ }_{585}$ [27] D. J. Inman, Engineering vibrations, Pearson Education (US), 1993.

[28] F. Fahy, D. Thampson, Fundamentals of sound and vibration, CRC press, 2014.

[29] K. J. Bathe, Finite element procedures, Prentice Hall, 2007.

[30] R. Allemang, D. Brown, A correlation coefficient for modal vector analysis, $1^{\text {st }}$ International Modal Analysis Conference, Orlando, USA, 1982.

[31] T. W. Wu, Boundary Element Acoustics: Fundamentals and Computer Codes, WIT Press, 2000. 
[32] LMS Virtual.Lab 15A, LMS Virtual.Lab Theory Manual and User Guide, Siemens PLM Software Inc (2015).

[33] GOM ATOS-I, GOM ATOS Professional Software Manual (2010).

[34] LMS SCADAS, LMS SCADAS brouchure, Siemens PLM Software Inc (2015).

[35] LMS Test.Lab 15A , LMS Test.Lab Signature Acquisition, User Guide, Siemens PLM Software Inc (2015).

600 [36] F. Jacobsen, Hans-Elias de Bree, Comparison of $P-P$ and $P-u$ sound intensity measurement systems, In:ICSV11, St.Petersburg, 2004. 